\title{
Editorial Articles
}

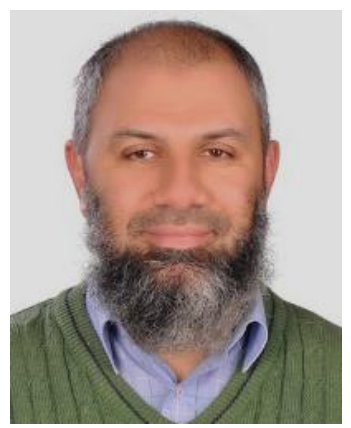

\section{Journal of Renewable Energy and Sustainable Development}

\author{
Prof. Yasser Gaber A. Dessouky
}

Energy is one of the basic needs of humanity and, for ages, the sun seemed to be the main source of all energy in the universe and that is why the ancient Egyptians used to venerate it. Many wastes and corpses - under pressure and heat - have been converted throughout the years inside the earth into the oil on which recent development is totally based to support humans' life, particularly in transportation and power generation. As time passes, it has been proven that oil will vanish. For the first moment, it seemed like mankind will certainly suffer due to such a hard situation and some people thought that we will get back to stone ages when oil no longer exists.

Thanks for the Renewable Energy scientist who has looked at the issue from a different prospective, that is, even if oil vanishes, the main reason of its existence is still there, that is the sun .

The sun has the capability to still make people enjoy their life not only by enjoying the sunny weather in many places of the world and having good times on the beach for those who live by the sea but also the sun can still provide man with required energy and cause the wind to blow, the waves to raise, the plants to be converted to biomass, and the earth to store its geothermal energy.

As long as life goes on, the sun will always rise and will always grant its energy to mankind. It is the clean, renewable and sustainable energy, which guarantees sustainable development.

Because of the high correlation between renewable energy and sustainable development, the editorial team of this journal thought of offering a hub to researchers interested in these two important fields to present their work and share it with others who have the same interest in such a wide area of research .

Thanks to the Academy Publishing Center, 'APC' owned by the Arab Academy for Science, Technology and Maritime Transport 'AASTMT' for hosting this international journal.

We call upon researchers in this area to share their thoughts and their work through this journal, free of charge through the online submission system, and have it on hard copy through a Print On Demand 'POD' base.

Last but not least, we would like to thank the authors of the four editorial articles which were useful to researchers in the field of Renewable Energy and Sustainable Development. 


\section{About Prof. Yasser Gaber A. Dessouky}

Professor Yasser Gaber Dessouky graduated from Alexandria University in 1991. He got his PhD from Heriot Watt University, UK in 1998. He is a professor at the Department of Electrical and Control Engineering, Arab Academy for Science, Technology and Maritime Transport (AASTMT) since 2006. Currently, he is the Dean of Scientific Research and Innovation in the AASTMT. He is the Chair of Industry Relations Subcommittee, IEEE Alexandria. He is a Renewable Energy Expert in the ESCWA of the UN and he is a member of the World Renewable Energy Network (WREN) UK and the DeserTech University Network (DUN) Hamburg Germany. He is also a member of the Research, Development and Innovation Network (RDIN) and the Egyptian Science, Technology and Innovation Observatory (ESTIO). Professor Dessouky is an editorial board member of many journals and a consultant for many industrial companies. He is a peer reviewer in many transactions, periodicals and conferences. He has a patent from the Patent Office in UK. He is leading Technology, Innovation and Commercialization Office (TICO) in the AASTMT. He is also leading many research projects funded by the EU such as ErAfrica project entitled, 'Development of a High-Efficient Power-Generation from Hybrid-Fuel Supplies', 2014-2017 and a TEMPUS project, 'Highway and Traffic Engineering', 2013-2016. 